\title{
Fetal imaging of a rare case of dural sinus malformation: a case report
}

\author{
Kavya S. Kaushik, Ullas V. Acharya", Rupa Ananthasivan, Bhavana Girishekar, Priyanka Kalidindi and Pooja G. Patil
}

\begin{abstract}
Background: Dural sinus malformations (DSM) are rare congenital anomalies, accounting for less than $2 \%$ of all intracranial vascular malformations. Fetal MRI plays an important role in the confirmation of the diagnosis, prognostication, and planning of treatment strategies. Here, we present a rare case of dural sinus malformation without thrombosis, diagnosed by prenatal ultrasound and fetal MRI. In addition to this, fetal intracranial 3D gradient recalled echo Dixon-based MRA was done which, to the best of our knowledge, is a first.
\end{abstract}

Case presentation: A 24-year-old multigravida with no known comorbidities underwent a routine second trimester anomaly scan in which an unusual posterior interhemispheric cyst was diagnosed. Further evaluation with fetal MRI revealed dilated posterior sinuses and torcula, normal internal jugular vein, and maintained flow voids with no mass effect. Fetal Dixon-based MRA and correlated Doppler revealed supply to the lesion by bilateral occipital arteries and posterior cerebral arteries. With these imaging features, a midline dural sinus malformation was diagnosed.

Conclusion: Dural sinus malformations should be considered in the differential diagnosis of unusual posterior fossa cystic lesions detected on antenatal ultrasound coupled with a colour Doppler examination. Prompt fetal MRI is essential to establish the diagnosis, identify intracranial complications and decide the postnatal treatment strategy, thereby possibly improving the postnatal outcome.

Keywords: Dural sinus malformation, DSM, Fetal MRI, Fetal intracranial MRA, Case report

\section{Background}

Dural sinus malformations (DSM) are rare congenital anomalies, accounting for less than $2 \%$ of all intracranial vascular malformations, which is recognisable on prenatal ultrasound scans [1]. Prenatal diagnosis has only been reported in about 50 cases thus far in literature [2]. Fetal MRI is a valuable tool for the confirmation of the diagnosis, prognostication and planning of treatment strategies. Here, we present a rare case of DSM without thrombosis, diagnosed by prenatal ultrasound, fetal MRI and fetal intracranial 3D gradient recalled echo (GRE) Dixon-based MRA.

\footnotetext{
*Correspondence: ullasva77@gmail.com

Department of Radiology, Manipal Hospitals, 98, HAL Old Airport Road, Kodihalli, Bengaluru 560017, India
}

\section{Springer Open}

\section{Case presentation}

A 24-year-old registered ANC, Gravida2 Para1 with a healthy first child, underwent an anomaly scan (at GA 21 weeks 5 days, elsewhere), in which an unusual posterior interhemispheric cyst was diagnosed. A follow-up scan at GA 27 weeks 2 days revealed normal interval fetal growth and persistent lesion. She was then referred to our hospital for further evaluation with fetal MRI.

Fetal MRI was done at gestational age of 28 weeks 4 days. Single-shot turbo spin echo (SS-TSE) sequences revealed ectatic dilatation of the torcula (confluence of the superior sagittal, straight, occipital and transverse sinuses), which extended to involve the posterior portion of the superior sagittal sinus, bilateral transverse sinuses and proximal sigmoid sinuses (right $>$ left), and part of the occipital sinus (Fig. 1) with maintained flow voids, thereby excluding thrombosis within.

(c) The Author(s). 2021 Open Access This article is licensed under a Creative Commons Attribution 4.0 International License, which permits use, sharing, adaptation, distribution and reproduction in any medium or format, as long as you give appropriate credit to the original author(s) and the source, provide a link to the Creative Commons licence, and indicate if changes were made. The images or other third party material in this article are included in the article's Creative Commons licence, unless indicated otherwise in a credit line to the material. If material is not included in the article's Creative Commons licence and your intended use is not permitted by statutory regulation or exceeds the permitted use, you will need to obtain permission directly from the copyright holder. To view a copy of this licence, visit http://creativecommons.org/licenses/by/4.0/. 


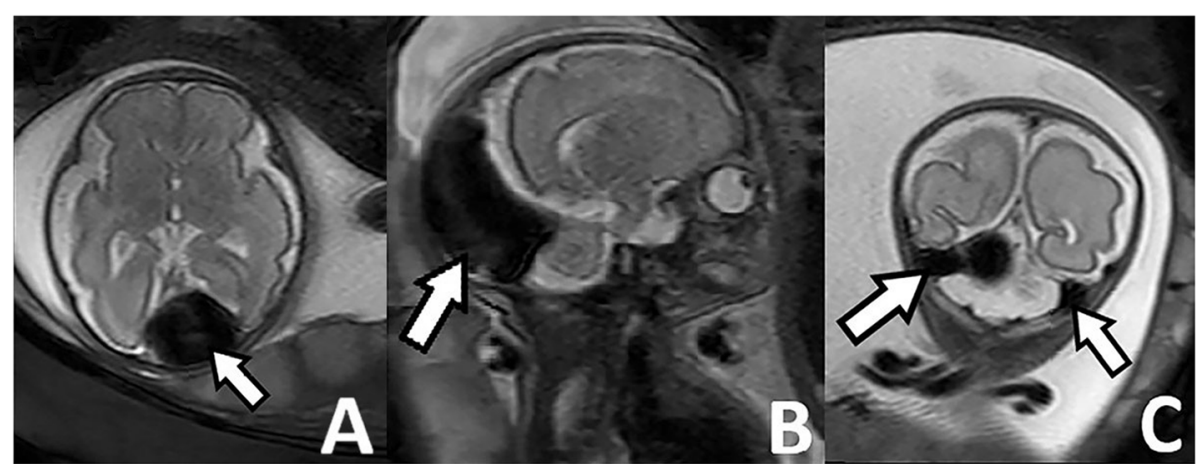

Fig. 1 Fetal MRI at 28 weeks 4 days-SS-TSE images of brain: A Axial, B sagittal and C coronal planes reveal abnormal ectatic torcula, posterior sagittal sinus and bilateral transverse sinuses, respectively. Flow voids are maintained, which excludes thrombosis

Fetal intracranial 3D GRE Dixon-based MRA revealed feeders to the torcula from bilateral occipital arteries (Fig. 2). Correlated Doppler study showed flow from bilateral posterior cerebral arteries also, with resultant arterialised flow within the torcula (Fig. 3). On DWI images, a suspicious focus of restricted diffusion with corresponding drop on ADC maps was seen in the right hemipons, possibly representing an acute ischemic insult (Fig. 4). Rest of the neuroparenchyma was normal. There was no mass effect on the surrounding structures or hydrocephalus.

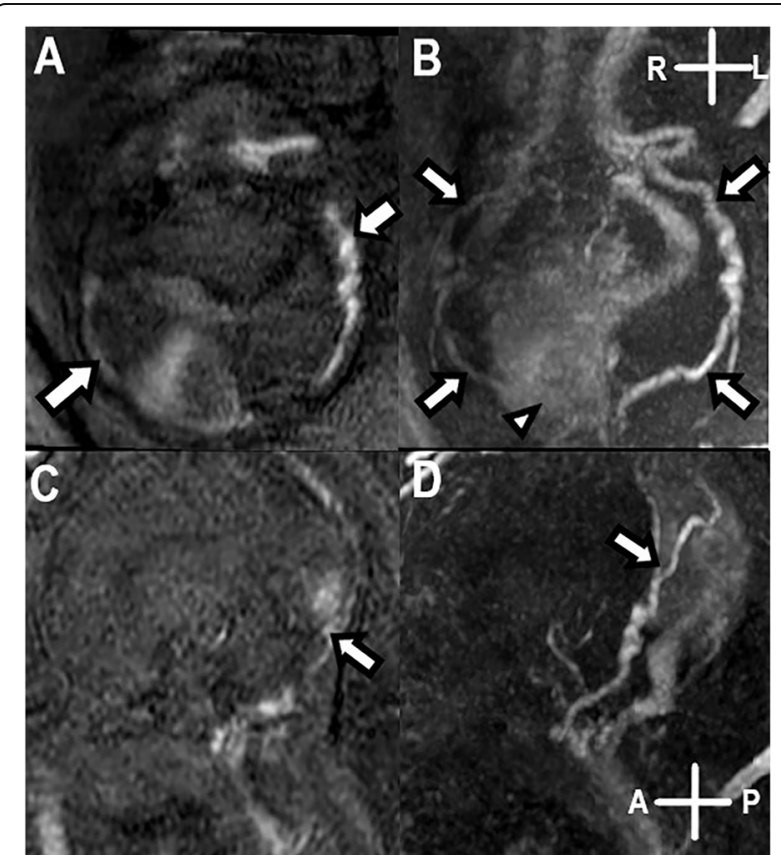

Fig. 2 Fetal MRI at 28 weeks 4 days - 3D gradient recalled echo Dixonbased intracranial MRA images: A, B Coronal thin and MIP images show prominent bilateral occipital arteries (arrows) supplying the DSM, which is also seen in the arterial phase being a venous structure (arrowhead). $\mathbf{C}$, D Sagittal thin and MIP images show the left occipital artery supplying the DSM. These represent the arterial feeders to the DSM
With the above findings, a midline type of DSM without thrombosis was diagnosed. A close follow-up was advised to look for the development of any thrombosis within the lesion and also for paucity of left limb movements in view of restricted diffusion in the right hemipons. A follow-up antenatal ultrasound with colour Doppler and a post-natal MRI were advised.

\section{Discussion}

Dural sinus malformation (DSM) is a rare congenital malformation which contains a dilated dural sinus pouch that communicates with the other sinuses and drains cerebral veins [3]. It belongs to the group of dural arteriovenous shunts, accounting for less than $2 \%$ of congenital intracranial vascular anomalies. Prenatal diagnosis has only been reported in about 50 cases thus far in literature.

They have been classified anatomically into a midline type and a lateral type, primarily based on the location. The former involves the posterior sinus with or without the torcula, with giant dural lakes and slow flow mural arteriovenous shunting, associated with spontaneous thrombosis, hemorrhagic infarction and a poorer prognosis. The latter involves the jugular bulb with otherwise normal sinuses and an associated high flow sigmoid sinus arteriovenous fistula. It has a good prognosis due to normal contralateral drainage pathway [4].

The etiopathological mechanism of development of DSM is debatable and many hypotheses have been put forth. The more commonly accepted theory considers that it results from excessive and disorganised development of the posterior sinuses, even when they should be decreasing in size $[1,5]$. Thrombosis is proposed to be a secondary effect rather than a causative phenomenon, due to possible local factors like immaturity of sinuses, disturbance of blood flow, and modification of the sinus endothelial lining [6]. However, recently it has been postulated that the normal gestational remodelling of the ballooned sinuses is impeded by the high venous 


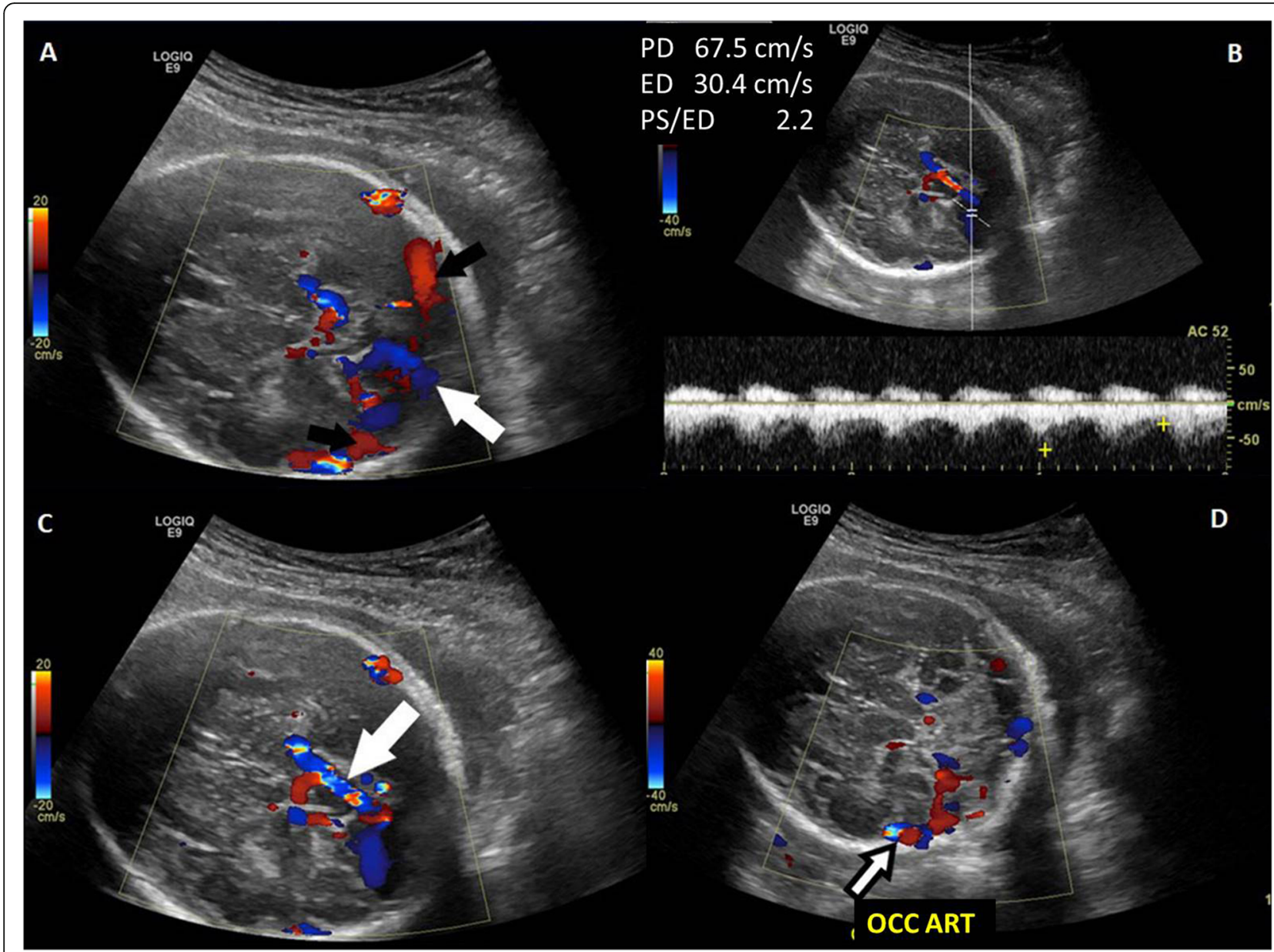

Fig. 3 Ultrasound at gestational age of 28 weeks 4 days_colour Doppler images of fetal brain: A Colour flow seen within dilated torcula (white arrow) and bilateral transverse sinuses (black arrows) with $\mathbf{B}$ arterialised flow seen within on spectral trace. C, D Blood supply to the torcula by posterior cerebral artery and occipital artery respectively

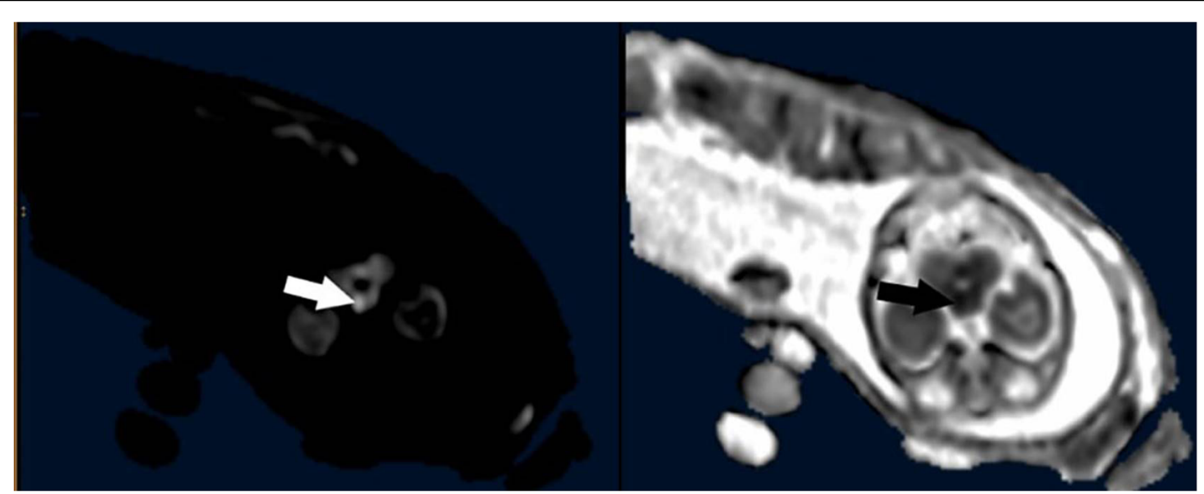

Fig. 4 Fetal MRI at 28 weeks 4 days-DWI and ADC maps of brain: Focus of restricted diffusion in the right hemipons with drop in signal intensity on corresponding ADC maps, represents a possible acute ischemic insult 
pressure due to the presence of dural arteriovenous fistulas and thus suggests a common mechanism for both antenatal and postnatal DSM [7].

Prenatal diagnosis is possible and sonography is the initial imaging modality of choice as well as for subsequent regular follow-up. Typical sonographic finding of DSM includes a huge anechoic cystic structure in the posterior fossa attached to the dura mater [8]. On colour Doppler, vascularity at the lateral margins of the lesion has been described with no detectable flow in the centre [9]. The marginal flow is postulated to represent multiple mural arteriovenous shunts usually associated with the lesion [4]. Failure to detect blood flow within the lumen has been attributed to its very low velocity [4], and in such cases altering the usual Doppler setting to low pulse repetition frequency and wall filters may aid in detecting flow within the lesion. Also, modern techniques such as $3 \mathrm{D} / 4 \mathrm{D}$ colour Doppler through transvaginal approach have been employed to detect vascularity and obtain additional structural data about the lesion [10].

There will be an increase in the possibility of missing this diagnosis if one is not aware of such an entity. Any such suspicious cystic focus should be investigated further with fetal MRI.

Fetal MRI is an essential imaging modality, to characterise and confirm the diagnosis of DSM and also identify any intracranial complications. Commonly, black blood techniques are used in fetal imaging. Profoundly hypointense signal is given by DSM on fast spin-echo T2 weighted sequences, as seen in our case [9]. However, if thrombosis is present, the signal can be iso-hyperintense on $\mathrm{T} 1$ and iso-hypointense on T2 depending upon the age of the thrombus. Resultant mass effect over the cerebellum, fourth ventricle and associated hydrocephalus has also been described in a few cases [2].

Bright blood techniques, mainly time of flight angiography (TOF), are widely used in postnatal imaging and hence their features on prenatal studies have not been described in literature. However, in our case, fetal 3D gradient recalled echo Dixon-based MRA was attempted and proved useful as it revealed arterial supply to the DSM.

Characteristic location and profound T2 hypointensity of venous pouch of DSM differentiates it from the more common fetal posterior cranial fossa lesions like DandyWalker malformation and retrocerebellar arachnoid cysts; vascular malformations, such as vein of Galen aneurysmal malformation; and congenital tumours like teratomas. While they may appear similar on ultrasound, fetal MRI easily distinguishes them [9].

According to the literature, the prognosis of patients with dural sinus malformation is still uncertain, and no prognostic criteria could be suggested for the fetus. The overall mortality rate is $15 \%$, with a favourable outcome seen in $87 \%$ of the surviving patients [11]. Factors in favour of a good neurological outcome were lateral type of DSM and antenatally detected thrombosis which either showed progressive decrease in size or spontaneous resolution [7, 11-13] .Presence of parenchymal infarctions, haemorrhage, hydrocephalus, congestive cardiac failure and non-resolution of thrombus or postnatal onset of thrombosis all contributed to poor prognosis resulting in either fetal/postnatal demise or a poor neurological outcome in the neonate $[7,11]$.

Diffusion-weighted imaging (DWI) helps in prognostication by demonstrating intralesional thrombosis and excluding potentially devastating intracerebral complications [14]. In our case, though no intrasinus thrombosis was seen, a small focus of restricted diffusion was seen in the right hemipons, likely representing an acute ischemic insult. There has been no literature that has reported the presence of an ischemic lesion on prenatal DWI in the absence of DSM thrombosis. Hence this finding is likely of inconclusive significance which needs follow-up.

Treatment strategies primarily aim at preserving venous drainage of the brain and depend on the angioarchitecture of the lesion. Multistage transarterial or transvenous endovascular embolisation with glue or coils is the primary therapeutic method [7, 13, 15]. In addition, medical treatment with heparin helps to prevent dural sinus thrombosis [15]. Surgical treatment in combination with embolisation has been shown to have positive clinical outcomes in neonates [15]. Information provided by MRI has a potential role in adjusting the treatment strategy to the postulated pathophysiology of symptoms and spontaneous vascular changes [9].

\section{Conclusion}

Dural sinus malformation is a rare congenital abnormality, a provisional diagnosis of which can be made on antenatal ultrasound. Prompt fetal MRI must be done to establish the diagnosis and identify intracranial complications. MRI also aids in better planning of timing and mode of delivery and the postnatal treatment strategy, resulting in better postnatal outcome. Following initial diagnosis, regular surveillance with ultrasonography is essential to document the morphological evolution of the DSM.

\section{Abbreviations \\ DSM: Dural sinus malformation; MRI: Magnetic resonance imaging; MRA: Magnetic resonance angiogram; SS-TSE: Single-shot turbo spin echo; TOF: Time of flight angiography; DWl: Diffusion-weighted imaging; ADC: Apparent diffusion coefficient}

Acknowledgements Not applicable. 


\section{Authors' contributions}

KK reviewed the literature and drafted the manuscript. UA contributed to the conception, analysis and critical revision of the manuscript. RA contributed to the conception, analysis and critical revision of the manuscript. BG contributed to literature review and drafting of manuscript. PK contributed to literature review and drafting of manuscript. PP contributed to literature review and drafting of manuscript. All authors have read and approved the manuscript.

\section{Funding}

This study was not supported by any funding.

\section{Availability of data and materials}

The datasets used and/or analysed during the current study are available from the corresponding author on reasonable request.

\section{Declarations}

\section{Ethics approval and consent to participate}

This report describes a rare diagnosis from routine diagnostic procedures. Hence, approval from the institutional review board was not required. Written informed consents for all the procedures were obtained before they were performed

\section{Consent for publication}

Written informed consent was obtained from the patient for publication of the case report and accompanying images.

\section{Competing interests}

The authors declare that they have no competing interests.

Received: 6 January 2021 Accepted: 2 July 2021

Published online: 14 July 2021

\section{References}

1. Barbosa M, Mahadevan J, Weon YC, Yoshida Y, Ozanne A, Rodesch G, Alvarez H, Lasjaunias P (2003) Dural sinus malformation (DSM) with giant lakes, in neonates and infants. Review of 30 consecutive cases. Interv Neuroradiol 9(4):407-424. https://doi.org/10.1177/159101990300900413

2. Xia W, Hu D, Xiao P, Yang W, Chen X (2018) Dural sinus malformation imaging in the fetus: based on 4 cases and literature review. J Stroke Cerebrovasc Dis 27(4):1068-1076. https://doi.org/10.1016/j.jstrokecerebrova sdis.2017.11.014

3. Mclnnes M, Fong K, Grin A, ter Brugge K, Blaser S, Haliday W et al (2009) Malformations of the fetal dural sinuses. Can J Neurol Sci 36(1):72-77. https://doi.org/10.1017/S031716710000634X

4. Lasjaunias P, Magufis G, Goulao A, Piske R, Suthipongchai S, Rodesch R, Alvarez H (1996) Anatomoclinical aspects of dural arteriovenous shunts in children. Review of 29 cases. Interv Neuroradiol 2(3):179-191. https://doi. org/10.1177/159101999600200303

5. Okudera T, Huang YP, Ohta T, Yokota A, Nakamura Y, Maehara F et al (1994) Development of posterior fossa dural sinuses, emissary veins, and jugular bulb: morphological and radiologic study. AJNR Am J Neuroradiol 15:1871-1883

6. Spampinato MV, Hardin V, Davis M, Chang E, Rumboldt Z (2008) Thrombosed fetal dural sinus malformation diagnosed with magnetic resonance imaging. Obstet Gynecol 111(2):569-572. https://doi.org/10.1097/ 01.AOG.0000289227.12531.03

7. Yang E, Storey A, Olson HE, Soul J, Estroff JA, Trenor CC, Cooper BK, Smith ER, Orbach DB (2018) Imaging features and prognostic factors in fetal and postnatal torcular dural sinus malformations, part II: synthesis of the literature and patient management. J Neurointerv Surg 10(5):471-475. https://doi.org/10.1136/neurintsurg-2017-013343

8. Komiyama M, Ishiguro T, Kitano S, Sakamoto H, Nakamura H (2004) Serial antenatal sonographic observation of cerebral dural sinus malformation. AJNR Am J Neuroradiol 25:1446-1448

9. Rossi A, De Biasio P, Scarso E, Gandolfo C, Pavanello M, Morana G et al (2006) Prenatal MR imaging of dural sinus malformation: a case report. Prenat Diagn 26(1):11-16. https://doi.org/10.1002/pd.1347
10. Lipa M, Kosinski P, Pooh RK, Wielgos M (2018) Prenatal diagnosis of dural sinus malformation in fetus presenting with edema. Ultrasound Obstet Gynecol 51(6):841-842. https://doi.org/10.1002/uog.18818

11. Gentilomo C, Cavaliere E, Manara R, Nosadini M, Sartori S, Suppiej A (2017) Foetal thrombosis of torcular herophili: report of two cases and review of the literature. Int J Neuro Disord Interv 2:109-113

12. Liby P, Lomachinsky V, Petrak B, Kyncl M, Charvat F, Padr R, Tichy M (2020) Torcular dural sinus malformations: a single-center case series and a review of literature. Childs Nerv Syst 36(2):333-341. https://doi.org/10.1007/s00381019-04280-3

13. Yang E, Storey A, Olson HE, Soul J, Estroff JA, Trenor CC, Cooper BK, Smith ER, Orbach DB (2018) Imaging features and prognostic factors in fetal and postnatal torcular dural sinus malformations, part I: review of experience at Boston Children's Hospital. J Neurointerv Surg 10(5):467-470. https://doi. org/10.1136/neurintsurg-2017-013344

14. Ebert M, Esenkaya A, Huisman TA, Bienstock J, Kalayci TO, Poretti A et al (2012) Multimodality, anatomical, and diffusion-weighted fetal imaging of a spontaneously thrombosing congenital dural sinus malformation. Neuropediatrics 43(05):279-282. https://doi.org/10.1055/s-0032-1324795

15. Liu CA, Chen HC, Luo CB, Guo WY, Mu-Huo Teng M, Chen HH et al (2012) Dural sinus malformation with arteriovenous fistulae in a newborn: positive outcome following endovascular management. J Chin Med Assoc 75(1):4346. https://doi.org/10.1016/j.jcma.2011.10.007

\section{Publisher's Note}

Springer Nature remains neutral with regard to jurisdictional claims in published maps and institutional affiliations.

\section{Submit your manuscript to a SpringerOpen ${ }^{\circ}$ journal and benefit from:}

- Convenient online submission

- Rigorous peer review

- Open access: articles freely available online

High visibility within the field

- Retaining the copyright to your article

Submit your next manuscript at $\boldsymbol{\nabla}$ springeropen.com 